\title{
Developing a Culturally-Relevant Genre-Based Writing Course for Distance Learning
}

\author{
Brian R. Morrison \\ Kanda University of International Studies, Japan \\ brian-m@kanda.kuis.ac.jp
}

\begin{abstract}
Learners with seemingly adequate linguistic abilities sometimes write in ways that are inappropriate in particular situations. This impacts on the intended communicative purpose, and for exam takers, the outcome is underperformance. This paper outlines the development and implementation of a short distance writing course that was designed to improve writing through a genre-based approach to second language writing (K. Hyland, 2005) and evolved using good non-native writing samples as exemplar texts (Tribble, 2005) to draw attention to language, in this case for IELTS exam writing. A key element of the course was the submission of multiple drafts, thus allowing a dialogue to develop, which in turn encouraged participants to consider how to come closer to genre expectations of organization and structure as well as improving the accuracy and sophistication of their texts.
\end{abstract}

\section{Background}

This course was developed at BEO, an organization based in Tokyo which specialises in placing potential students in further and higher education institutions in the UK and other English-speaking countries. In addition to helping with course selection and the application process, the company offers exam preparation and skill-specific pre-sessional classes such as GMAT Preparation, Academic Discussion and Presentation Skills, and Academic Writing. The majority of tuition inquiries are for part-time courses, and most of these inquiries are from people interested in postgraduate studies. The other significant groups are undergraduates aiming for one-year study abroad programmes or people interested in their first experience of higher education at UK colleges and universities.

In order to enter further and higher education in the UK, a minimum score on an exam such as IELTS is a common requirement for applicants to whom English is not a first language. Therefore, many people contacting BEO have an interest in taking this exam to fulfill one of the conditions for university acceptance. Indeed, since offering IELTS tuition, these classes have always attracted the greatest enrolments.

The need for an IELTS distance course was identified in two ways. The first was counselling and level-testing sessions with clients aiming for overseas studies. Some applicants needed to improve their language skills, but were unable to attend classes due to a mismatch between the timetable and their availability. An alternative to attending scheduled classes was to take one-to-one lessons; however, this was not always a feasible option. The second factor that raised the possibility of a distance course was that the one-to-one classes were almost always IELTS-related, and of these, around $80 \%$ were requests for IELTS writing instruction.

Language Education in Asia, 2010, 1(1), 171-180. http://dx.doi.org/10.5746/LEiA/10/V1/A15/Morrison 
Private classes were always designed around the learner's wants and needs, and when appropriate, were informed by a writing task given prior to the first lesson. During these lessons, strategies and language related to the skills were identified and practiced. The teacher responsible for IELTS delivery identified common themes found across individual learners (Table 1). This knowledge, combined with the potential market for a distance course, allowed for the course development to proceed.

\section{Curriculum Design}

\section{Planning the Syllabus}

The content for the lesson packs was initially considered through a general needs analysis. This was done by a course designer familiar with problems encountered by IELTS writers in his role as a teacher and IELTS assessor. Nevertheless, it was important to also analyse written submissions from the target group. Samples of writing were gathered from 27 students from a variety of classes, all of whom were studying academic writing or IELTS preparation. The course designer then identified the areas where these Japanese learners regularly had problems. These problem areas were then grouped roughly according to the four main grading criteria in the IELTS exam: task achievement, coherence and cohesion, vocabulary, and grammar.

\section{Table 1}

\section{Common Problem Areas Grouped by Grading Category}

\begin{tabular}{|c|c|}
\hline Grading Category & Common Problem Areas \\
\hline Task Achievement & $\begin{array}{ll}\text { - } & \text { Mechanical recounting of data } \\
\text { - } & \text { No overview } \\
\text { - } & \text { Insufficient word length } \\
\text { - } & \text { Insufficient development } \\
\text { - } & \text { Overgeneralisation, i.e., a tendency not to hedge }\end{array}$ \\
\hline $\begin{array}{l}\text { Cohesion and } \\
\text { Coherence }\end{array}$ & $\begin{array}{l}\text { - Inadequate introductory paragraphs } \\
\text { - } \quad \text { Ino paragraphing (one paragraph or sentences) } \\
\text { - } \quad \text { Lack of linking between sentences } \\
\text { - Lack of paragraph transitions } \\
\text { - } \quad \text { Lack of support for paragraphs } \\
\text { - Sentence-initial it misapplied }\end{array}$ \\
\hline Vocabulary & $\begin{array}{ll}- & \text { Lack of synonymy } \\
\text { - } & \text { Over-reliance on simple vocabulary } \\
\text { - } & \text { Collocation errors } \\
& \text { Misuse, e.g., aggressive vs. assertive } \\
\end{array}$ \\
\hline Grammar & - $\quad$ Varied according to individual students \\
\hline
\end{tabular}

Once the common problem areas were established, the course syllabus was mapped out by considering areas where the materials could focus the learners' attention to address these problems. The syllabus was then divided into lesson aims to decide how many lesson packs would constitute the course. This was revised down due to commercial constraints into two separate modules of five lessons and the potential extra material was divided amongst the remaining lessons to produce the outline below (Table 2), thus allowing material production to focus on these areas.

It is important to note that although there was separation in the syllabus outline, the lessons were not mutually exclusive. For example, signalling devices and concluding paragraphs were 
part of the model essays given, but not explicitly referred to until lessons 4 and 5, respectively. Likewise, further discussion of previous lessons and instructions to identify features and language in earlier models were common.

\section{Table 2}

\section{The Syllabus}

\begin{tabular}{|c|c|c|}
\hline & Task 1 & Task 2 \\
\hline Lesson 1 & Introductory paragraph & Introductory paragraph \\
\hline Lesson 2 & $\begin{array}{l}\text { Compare \& contrast } \\
\text { Range of vocabulary } \\
\text { Paragraph organisation }\end{array}$ & $\begin{array}{l}\text { Organising main paragraphs } \\
\text { Paragraph transition } \\
\text { Coherence and cohesion }\end{array}$ \\
\hline Lesson 3 & $\begin{array}{l}\text { Describing trends } \\
\text { Range of vocabulary } \\
\text { Paragraph organisation }\end{array}$ & $\begin{array}{l}\text { Lexical sophistication } \\
\text { Synonymy } \\
\text { Academic Word List }\end{array}$ \\
\hline Lesson 4 & $\begin{array}{l}\text { Describing a process } \\
\text { Signalling devices }\end{array}$ & $\begin{array}{l}\text { Hedging } \\
\text { Complex grammar }\end{array}$ \\
\hline Lesson 5 & $\begin{array}{l}\text { Describing a map } \\
\text { Summary paragraph }\end{array}$ & Concluding paragraph \\
\hline
\end{tabular}

\section{Approach to Materials Production}

When designing materials for writing, the purpose of writing should be considered. This allows an approach to be selected based on principled decisions. The process approach focuses on writers and the various processes they go through before the text reaches the finished stage. The genre approach, by contrast, focuses on the readers and their expectations. Given that the intended readers in an IELTS exam are the examiners, it is vital that the writer meets these readers' expectations. Thus the under-emphasis on product taken when implementing a process approach is less effective for writing courses, such as those connected with exams, where meeting reader expectations is paramount.

Some critics of the genre approach claim it stifles creativity and muffles personal voice. However, making genres explicit is not inherently prescriptive. Whether the text is an invoice or an IELTS writing task, each genre does restrict the writer. To argue against genre restriction is disingenuous. As K. Hyland (2005) so succinctly puts it, "A genre that does not restrict is not a genre." Likewise, a successful piece of writing may flout conventions, but its success is in knowing what the conventions are and how to flout them (Tribble, 2005; White, 2005). However, within an exam situation, flouting conventions is not recommended.

Having established why a genre approach is relevant, it is important to consider what this means in practice. There are two main points that differentiate process from genre when developing materials and teaching. The first is that the genre approach advocates providing models for the writer to analyse, since genre conventions vary according to several factors, not least of these being culture and language. It is therefore important that learners are aware of acceptable register and other conventions in their target genre. The second is explicit instruction, a cornerstone of the genre approach. Previous exposure to target genres is not enough: there is no direct relationship that has been established between the amount read and the quality of students' written work. Although good writers are often prolific readers, prolific readers are not always good writers (Stainthorp, 2005). Exposure to a target genre is important, but explicit analysis is deemed necessary with this approach. These reasons for implementing the genre approach are not new (Derewianka, 2003); however, producing materials which adhere to these principles may be more problematic. 


\section{Materials Production}

The course designer on this project had a bank of writing resources developed for writing classes. He wrote numerous example essays and integrated these with adapted versions of relevant resources into the distance materials. These were designed to guide learners to investigate the interaction between language, function, and structure in the model texts.

The new resources were piloted with a variety of one-to-one students in class as they became ready. The first trials with the material were not as successful as envisioned. It soon became apparent that rather than providing a perfect example essay, the exemplar texts were impenetrable walls of words that had students reaching for their dictionaries. Not only were the model essays too difficult for the learners, they were also inappropriate, as will be discussed below. In addition, by using multiple examples from one writer, the central tenets of the genre approach had been misunderstood.

There were two main reasons why the texts were inappropriate. The first was rather straightforward: these learners were aiming for an IELTS score somewhere between 5.5 and 7.0, and to provide an overly complex model was setting an unachievable target. The second reason was perhaps less obvious: the content was potentially unfamiliar. The arguments, support, examples, and scenarios used in writing an IELTS essay reflected the course designer's own outlook and worldview, and were influenced heavily by the social narrative he was exposed to. Since the course designer and students were from different countries, different educational backgrounds, and to a certain extent different generations, there was sometimes a misalignment in narrative, in what was considered general knowledge, and in interpretation of intent.

This problematic trialing seemed like an opportune moment to apply what Tribble (2005) advocated when providing written models: rather than consider native-speaker texts, use good models by expert writers. In this case, expert writers could be viewed as those who had achieved an IELTS score of 7.0 or higher. Therefore, by replacing the native-speaker models with examples by a variety of good local IELTS writers who had gone on to achieve the required grade, the replacement texts provided a more realistic target, i.e., a target which learners could successfully hit. Texts were altered slightly, but only to correct minor linguistic errors so that formulaic sequences could be reused without transferring imbedded inaccuracies.

It soon became clear when piloting the materials in subsequent lessons that the language was clear and understandable; the ideas were familiar, and support for these ideas typically focused on Japan, Asia, and views that were familiar. By contrast, the course designer's ideas and views evident in his writing reflected his beliefs and those of his peers, which were at times quite different from Japanese learners and their peers. For example, the course designer's essay on the merits of free education was replaced with the more common consensus in Japan that free education would be abused by lazy students.

With the source of the models decided, it was still important to consider how to encourage learners to use the material for their own means. As well as utilizing worksheets that, for example, highlighted signalling devices, raised awareness of structure, and considered academic lexis through categorizing, matching exercises, and gap-fills, there were formulaic sequences in the model texts that students should be encouraged to notice and use. Warren's (2000) investigation (as cited in Schmitt \& Carter, 2004) calculated such sequences comprise over $50 \%$ of written discourse. With such a large proportion of text being thus constructed, it seemed apposite to incorporate awareness and use of formulaic sequences into a writing course. 
The ubiquity of formulaic sequences is only one reason to encourage learners to use them. They also lower cognitive processing and make production more efficient (Wray, 2000). Therefore, lexical phrases can help students write more fluently within a genre if they are able to select suitable sequences, understand appropriate application, and memorize these chunks for future writing. Some formulaic sequences have application across multiple genres. Many of those relevant in IELTS exams are equally relevant in other academic writing, including assignments, reports, and dissertations. If selection and application skills can be developed, the learner is potentially better equipped to apply them to other text types without a teacher, i.e., the learner can become more autonomous.

Therefore, the course encouraged students to underline words and phrases from the model texts and their own submissions that they could re-use in their later essays, i.e., genre-appropriate language was lifted in chunks. Learners were also encouraged to compile a phrasebank. This is not a new idea; indeed, The University of Manchester's phrasebank (2005) exists online for students writing at university level. Nevertheless, while Jones and Haywood (2004) provided a list to their students, in this course, learners were encouraged to choose for themselves. In other words, autonomy was fostered as the onus moved on to the student to analyse, evaluate, and collect. Encouraging learners to identify and integrate appropriate formulaic sequences not only had the potential to allow writers to increase their speed and add grammatical complexity, but perhaps more importantly, there was the potential for writing to look more "natural," to become genre-appropriate, and to be accepted by the discourse community to which the learners aspired.

\section{Course Management}

A key element of the course was the submission of multiple drafts via email. Previous experience with workshops and multiple-draft submission had highlighted a need for specific deadlines to be incorporated in the course to allow it to be managed more easily. Without the deadlines, some students waited weeks or even months between submissions. This created problems in managing teachers' workloads and meeting student expectations of turnaround time. Dudeney and Hockly's (2006) recommendation for clear deadlines on distance courses was followed, as it allowed the workload and expectations of teachers and learners to be more easily managed. Indeed, when asked their opinions about the deadlines following the course, the vast majority of respondents stated that it helped them to plan their own studying more effectively.

Weekly deadlines were set so that the course participants worked their way through a lesson and submitted two essays a week. The first draft of an IELTS task was received every Monday by midday; teacher feedback was given and returned to the student by the middle of the week. By the following Monday, a second draft was expected, in addition to the first draft of the next IELTS essay. The deadlines and movement of essays are outlined below (Table 3). 


\section{Table 3}

\section{Course Management}

\begin{tabular}{|c|c|c|}
\hline & Monday Deadline & Thursday Deadline \\
\hline Week 0 & \multicolumn{2}{|c|}{ Start date confirmed and materials emailed to student. } \\
\hline Week 1 & Essay 1 - Submission 1 & Essay 1 - Feedback 1 \\
\hline Week 2 & $\begin{array}{l}\text { Essay } 1 \text { - Submission } 2 \\
\text { Essav } 2 \text {-Submission } 1\end{array}$ & $\begin{array}{l}\text { Essay } 1 \text { - Feedback } 2 \\
\text { Essay } 2 \text { - Feedback } 1\end{array}$ \\
\hline Week 3 & $\begin{array}{l}\text { Essay } 2 \text { - Submission } 2 \\
\text { Essay } 3 \text { - Submission } 1\end{array}$ & $\begin{array}{l}\text { Essay } 2 \text { - Feedback } 2 \\
\text { Essay } 3 \text { - Feedback } 1\end{array}$ \\
\hline Week 4 & $\begin{array}{l}\text { Essay } 3 \text { - Submission } 2 \\
\text { Essay } 4 \text { - Submission } 1\end{array}$ & $\begin{array}{l}\text { Essay } 3 \text { - Feedback } 2 \\
\text { Essay } 4-\text { Feedback } 1\end{array}$ \\
\hline Week 5 & $\begin{array}{l}\text { Essay } 4 \text { - Submission } 2 \\
\text { Essay } 5-\text { Submission } 1\end{array}$ & $\begin{array}{l}\text { Essay } 4-\text { Feedback } 2 \\
\text { Essay } 5 \text { - Feedback } 1\end{array}$ \\
\hline Week 6 & Essay 5 - Submission 2 & Essay 5 - Feedback 2 \\
\hline
\end{tabular}

The amount of work required for feedback to be given was seen as approximately equivalent to half an hour of teaching time. This was used when costing the course and calculating teacher remuneration.

\section{Dialogue}

As well as dialogue developing through feedback, which will be elaborated on in the next section, there was dialogue in the emails between teacher and student. These generally contained the usual salutations, comments on the weather, and requests for information, i.e., they tended to conform to genre expectations. They allowed some teacher-student interaction beyond teaching and learning and were important for providing an opportunity for the two people to show interest in each other, much as teachers and students often do in the classroom.

In addition to the social interaction through email, teachers also offered to answer any further questions or explain their comments if students required further clarification. In this respect, written negotiation of meaning substituted for the more immediate face-to-face discussions available in a classroom. The medium and the explicit offer did seem to encourage students to be more forthcoming with questions or requests for clarification and advice. Perhaps then distance courses may have an advantage over larger classrooms for students who are more reluctant to seek clarification in front of their peers.

\section{Writing Feedback}

As mentioned previously, the material was based around a general needs analysis of students attending classes at this particular institution. Nonetheless, once the first piece of written work was received, it was then a lot easier to evaluate where individual learners were with their writing and what changes they could realistically make to bring their writing closer to genre expectations. However, given the lack of face-to-face interaction, it was difficult to ascertain what students could do rather than what the students had done. In other words, the learners might not have been applying some of their writing abilities due to a misunderstanding of task requirements or genre expectations. Therefore, first draft feedback highlighted what the students had done well and how the writing could be improved.

Since feedback was based on individual student needs, each piece of written work was an opportunity to analyse these needs. The first drafts were an indication of the present situation, while the second drafts gave an indication of a realistic target, i.e., one that was attainable as a first draft within a short time frame. In other words, if students were redrafting in their own words, it followed that the second draft gave a clear indication of how the students could write a 
first draft before too long. Thus learners were laying the path before them just before they moved on to it. The teacher helped guide learners to their destination based on their needs and preferences.

The time allocated for feedback on this course allowed teachers to elaborate on their comments, another of the advantages of the distance course. Therefore, using their knowledge of IELTS grading criteria and what a student could feasibly achieve, the teachers exercised judgment over what to give feedback on. The point was to provide enough feedback to guide the student to write in a way that would be closer to genre expectations without overwhelming, and potentially demotivating the learner. After all, the findings of both Sheppard (1992, as cited in Truscott, 1996) and Semke (1984, as cited in Truscott, 1996) suggested that error feedback could lead learners to strategies that resulted in simpler or less fluent writing. In an attempt to address this issue, importance was given to highlighting what the learner had done well, explaining why it was good, and later commenting on the areas in which the learner was becoming more successful. This echoes F. Hyland's (2001) assertion that feedback "serves an important function in motivating and encouraging students" (p. 233).

Teacher feedback in this distance course utilized the editing tools in Microsoft Word which allow comments to be added and any changes to be tracked. There are numerous ways of giving feedback, and the effectiveness of these ways has been debated and investigated since Truscott (1996) first questioned the validity of much of the research. Nevertheless, giving feedback allowed a dialogue to develop, which in turn encouraged participants to consider how to come closer to genre expectations of organization and structure, as well as improving the accuracy and sophistication of their texts. Several studies concluded that:

Feedback is not simply disembodied reference to student texts, but an interactive part of the whole context of learning, helping to create a productive interpersonal relationship between the teacher and the individual students. (Hyland \& Hyland, 2006, p. 86)

In this course, initial feedback on the first draft used comment boxes to give specific guidance on what was done well, where errors existed and how certain areas could be improved even when free of errors. This goes beyond written corrective feedback and the typology Ellis (2009) proposes. Although Ellis (2009) acknowledges that his typology is limited to the correction of linguistic errors, the error focus in the research he cites appears to take a rather narrow view of writing, a view which values accuracy over other indicators of good writing, such as purposeful communication and meeting the needs of the reader.

The IELTS grading system, by contrast, grades four specific areas. Accuracy in grammar and vocabulary choices influences the grade in each of the eponymous categories, but not at the expense of complexity and sophistication. Indeed, complex grammar containing errors is viewed more favourably than accuracy that relies on simple structures. Likewise, less common lexis is preferable to a restricted range of simple vocabulary, even when the former is used with less accuracy, as long as the meaning is clear. The other two grading criteria, task achievement and coherence and cohesion, are equally important. Candidates aiming for 7.0 are not expected to write two error-free essays; however, they can only achieve the target if they have answered the questions, supported their answers, structured their writing appropriately, and shown a range of grammatical structures and sophisticated lexis. These points should therefore inform the range of feedback that could be given to the learner. 
On this course, the types of initial feedback on the first draft were a variety of the following and examples are provided in brackets after each. The first three categories are noticeably absent in Ellis' (2009) typology.

- Commenting on what is good about the essay and its constituent parts (Your idea is clear and well supported in this paragraph - good work.)

- Encouraging learners to push their abilities (Normally this is fine, but judging by your work, I'm sure your vocabulary is good enough to substitute a more sophisticated verb.)

- Giving direction on content (In paragraphs 2 and 3 you identify two negative aspects to living in a city, but you never say why they are negative. If you can do that and make a few adjustments to phrases, this will be much better.)

- Direct prescriptive instruction (Do not use contractions.)

- Identifying where errors occur by highlighting and adding notes (wrong word, wrong form, missing word)

- Pointing out systematic errors that the learner may be able to identify and reformulate

(You have used "of" a lot as a preposition. Sometimes you have used it incorrectly. Read through your essay and decide which phrases you think use it well and which you are not sure about. Try to correct the errors either by changing the preposition or giving a more natural phrase by deleting "of" and changing the word order.)

- Giving a more thorough explanation of a particular grammar point that the writer is struggling with and providing links to self-study material

(There are still a few problems with articles, but I have given a brief summary below of the main areas you seem to be having problems with.

Some phrases commonly use "the." Instead of learning more grammar, you could learn the phrases.

The first + noun phrase

The second + noun phrase

The last + noun phrase

Superlatives always start with the: The most / the least / the largest / the smallest

For more practice, you could try this interactive activity:

http://www.bankgatetutors.co.uk/article_cloze.htm

And this one from the BBC has some explanation and a few quizzes in the menu bar on the left.

http://www.bbc.co.uk/worldservice/learningenglish/radio/specials/1521_gramch allenge27/index.shtml)

At the end of the essay, the teacher always gave a note summarizing the inter-text feedback, identifying what was good about the writing and indicating what to concentrate on for the second draft, e.g.: 
You've done a good job - the first paragraph is perfect.

The second paragraph could be added to in order to support your main idea here.

A few of the following phrases could also be added to show how everything

relates to each other:

with regards to

it is clear that

separate

main

The third paragraph is a little bit odd - you have written from the point of view of the university, but it should really be about the student. For example, you could write: the student / applicant receives an offer from the university $\mathbf{O R}$ an offer is received by the student / applicant.

Although the passive voice is important in this essay, you can choose to vary it with the active voice - it doesn't have to be all passive. The examiners are looking for a variety of grammatical structures because this can make the essay more interesting to read.

Add a little bit more to the summary - perhaps something about the number of stages.

The second draft received a different approach for feedback. With this version, the feedback was limited to "direct teacher editing," i.e., correcting or rewording anything that the writer was guided to, but unable to rectify. This then provided a further model, but one that was borne out of collaboration between the learner and the teacher. Thus, not only were non-native speaker models incorporated into the materials, but user-generated models were also added as the course progressed. Although the learners were not required to redraft further, there was a task. Learners were asked to note down words and phrases that could be reused in subsequent essays. This required learners to re-read, value, and analyse their own work with a view to improving subsequent writing. This brought together the main strands of this course: a genre approach, appropriate exemplar texts generated by non-native writers of English, autonomy development through guided choice, and formulaic sequence use.

Questionnaires given after the course showed that respondents unanimously felt that the feedback made them more competent writers. When asked about the two different feedback styles, these were both valued by all. The vast majority specifically commented on how beneficial they felt their own rewriting was to their development as writers. They also noted that the feedback had helped them identify what they were doing well as well as what they had to improve upon, with a specific comment referring to the development of a greater awareness of the comparative rhetoric of English and Japanese.

\section{Conclusion}

For anyone to attempt to become part of the discourse community they aspire to, it is necessary for him or her to have an awareness of what the acceptable genre is. An obvious way to do this is to analyse some accessible real examples to notice the way the language is structured. The writer can then use a similar format as a guide to inform the construction of the text, incorporate appropriate language, and at appropriate stages receive feedback from a suitable reader. The feedback can guide the writer to improve communicative intent and meet the readers' genre expectations. This article evolved this way.

A similar approach to L2 writing seems valid and principled. More accomplished L2 writers are likely to be doing this already. However, for those who are seeking instruction, providing them 
with the skills to use good exemplar texts as a lexical resource potentially enables writers to become more autonomous. The feedback guides and the dialogue which develops go far beyond a mechanical monologue of error identification. While face-to-face class time is absent in distance learning, there are gains in the time that can be devoted to writer-specific feedback. The combination of these factors results in a course that delivers language learning out of class and prepares writers for learning beyond the course.

\section{Biodata}

Brian R. Morrison has an MA (ELT) from the University of Reading and is a Learning Advisor in the Self-Access Centre at Kanda University, Japan, where he produces materials, develops courses, supports students, and promotes self-directed learning. His previous experience includes teaching in Hungary, Portugal, Macedonia, and his native UK.

\section{References}

Derewianka, B. (2003). Trends and issues in genre-based approaches. RELC Journal, 34(2), 133-154. http://dx.doi.org/10.1177/003368820303400202

Dudeney, G., \& Hockly, N. (2006). The wired teacher: Skills for the online tutor. English UK workshop.

Ellis, R. (2009). A typology of written corrective feedback types. ELT Journal, 63(2), 97-107. http://dx.doi.org/10.1093/elt/ccn023

Hyland, F. (2001). Providing effective support: Investigating feedback to distance language learners. Open Learning, 16(3), 234-247. http://dx.doi.org/10.1080/02680510120084959

Hyland, K. (2005). Working with writing: Texts, writers and readers. Paper presented at IATEFL $\mathrm{ES}(\mathrm{O}) \mathrm{L}$ and Research SIGs, Writing Revisited: New Approaches to Second Language Literacy, Cambridge, UK.

Hyland, K., \& Hyland, F. (2006). Feedback on second language students' writing. Language Teaching, 39(2), 83-101. http://dx.doi.org/10.1017/S0261444806003399

Jones, M., \& Haywood S. (2004). Facilitating the acquisition of formulaic sequences. In N. Schmitt (Ed.), Formulaic Sequences (pp. 269-300). Philadelphia, PA: John Benjamins.

Schmitt, N., \& Carter, R. (2004). Formulaic sequences in action: An introduction. In N. Schmitt (Ed.), Formulaic Sequences (pp. 1-22). Philadelphia, PA: John Benjamins.

Stainthorp, R. (2005). Writing: The ultimate juggling act. Paper presented at IATEFL ES(O)L and Research SIGs, Writing Revisited: New Approaches to Second Language Literacy, Cambridge, UK.

Tribble, C. (2005). Standards for academic writing. Paper presented at IATEFL ES(O)L and Research SIGs, Writing Revisited: New Approaches to Second Language Literacy, Cambridge, UK.

Truscott, J. (1996). Review article: The case against grammar correction in L2 writing classes. Language Learning, 46(2), 327-369.

http://dx.doi.org/10.1111/j.1467-1770.1996.tb01238.x

University of Manchester. (2005). Academic Phrasebank [online]. Retrieved from: http://www.phrasebank.manchester.ac.uk/

White, R. (2005). Insights into writing. Paper presented at IATEFL ES(O)L and Research SIGs, Writing Revisited: New Approaches to Second Language Literacy, Cambridge, UK.

Wray, A. (2000). Formulaic sequences in second language teaching: Principles and practice. Applied Linguistics, 21(4), 463-489. http://dx.doi.org/10.1093/applin/21.4.463 